\title{
Aberrant expression of microRNA-99a and its target gene mTOR associated with malignant progression and poor prognosis in patients with osteosarcoma
}

\author{
This article was published in the following Dove Press journal: \\ OncoTargets and Therapy \\ 17 March 2016 \\ Number of times this article has been viewed
}

\author{
Jiali Zhao ${ }^{1,2, *}$ \\ Fengli Chen ${ }^{3, *}$ \\ Quan Zhou ${ }^{2}$ \\ Wei Pan² \\ Xinhong Wang ${ }^{2}$ \\ $\operatorname{Jin} \mathrm{Xu}^{2}$ \\ Li $\mathrm{Ni}^{1}$ \\ Huilin Yang' \\ 'Department of Orthopedics, \\ The First Affiliated Hospital of \\ Soochow University, Suzhou, \\ ${ }^{2}$ Department of Orthopedics, \\ The Affiliated Huai'an Hospital of \\ Xuzhou Medical College and The \\ Second People's Hospital of Huai'an, \\ Huai'an, ${ }^{3}$ Central Laboratory, Huai'an \\ First People's Hospital, Nanjing \\ Medical University, Huai'an, Jiangsu, \\ People's Republic of China \\ *These authors contributed equally \\ to this work
}

Background: The mammalian target of rapamycin (mTOR) has been reported to act as a target gene of microRNA (miR)-99a in various cancer cells and identified as an independent prognostic marker of human osteosarcoma. The aim of this study was to investigate the clinical significance of miR-99a/mTOR axis in human osteosarcoma.

Methods: A total of 130 pairs of osteosarcoma and matched noncancerous bone tissues were used to detect the expression levels of miR-99a and mTOR mRNA by quantitative real-time polymerase chain reaction. Then, associations of miR-99a and/or $m$ TOR expression with clinicopathological features and prognosis of patients with osteosarcoma were statistically analyzed. Results: The expression levels of miR-99a (tumor vs normal: $2.11 \pm 1.03$ vs $4.69 \pm 1.21, P<0.001$ ) and $m$ TOR mRNA (tumor vs normal: $4.40 \pm 1.13$ vs $1.74 \pm 0.85, P<0.001$ ) in osteosarcoma tissues were, respectively, lower and higher than those in noncancerous bone tissues. The expression levels of miR-99a in osteosarcoma tissues were negatively correlated with those of $m T O R$ mRNA. Additionally, miR-99a-low and/or mTOR-high expression were all significantly associated with advanced surgical stage, positive metastasis and recurrence, and poor response to chemotherapy (all $P<0.05$ ). Moreover, patients with osteosarcoma with miR-99a-low and/or mTOR-high expression had shorter overall and disease-free survivals than those in miR-99a-high and/or $m T O R$-low expression groups. Multivariate Cox analyses showed that miR-99a and/or mTOR expression were all independent prognostic factors of osteosarcoma.

Conclusion: Our data showed the crucial role of miR-99a/mTOR axis in the malignant progression of human osteosarcoma, implying that conjoined expression of miR-99a and mTOR may offer an attractive novel prognostic marker for this disease.

Keywords: microRNA-99a, mammalian target of rapamycin, osteosarcoma, quantitative real-time PCR, prognosis

\section{Introduction}

Osteosarcoma, the most frequent primary malignant sarcoma of the bone in adolescents and young adults, derives from primitive bone-forming mesenchyme. ${ }^{1}$ This disease has an estimated annual incidence rate of 4 million worldwide. ${ }^{2}$ Despite great progress in therapeutic strategies, including surgery, adjuvant chemotherapy, radiotherapy, and biological therapy, the prognosis of patients with osteosarcoma remains unsatisfactory due to bone destruction, neoplastic bone formation, and pulmonary metastasis. ${ }^{3}$ Approximately $80 \%$ of patients with osteosarcoma eventually develop recurrent metastatic osteosarcoma following surgical operation, and the 3-year survival rate after pulmonary metastasectomy
Correspondence: Huilin Yang Department of Orthopedics, The First Affiliated Hospital of Soochow University, I88 Shizi Street, Suzhou 215006, Jiangsu, People's Republic of China Tel/fax +865I26778 0I0I

Email haeyspine@।63.com (c) 1 (1) 2016 Zhao et al. This work is published and licensed by Dove Medical Press Limited. The full terms of this license are available at https://www.dovepress.com/terms.php hereby accept the Terms. Non-commercial uses of the work are permitted without any further permission from Dove Medical Press Limited, provided the work is properly attributed. For permission for commercial use of this work, please see paragraphs 4.2 and 5 of our Terms (https://www.dovepress.com/terms.php). 
is $\sim 30 \% .{ }^{4}$ Several clinicopathological features, such as tumor size, response to chemotherapy, and metastasis status, have been used as prognostic indicators for patients with osteosarcoma, but they lack sensitivity and specificity. Similar to other malignancies, it is a multistep process with accumulation of complex molecular changes in the development and progression of osteosarcoma. However, the underlying molecular mechanism of this disease has not been fully elucidated.

MicroRNAs (miRs), a class of endogenous, noncoding, short (18-25 nucleotides in length), single-stranded RNA molecules, are regarded as negative regulators of gene expression at the posttranscriptional level through binding to the $3^{\prime}$ untranslated region of target mRNAs, leading to translational inhibition and/or mRNA degradation., ${ }^{5,6}$ Growing evidence shows that miRs play crucial roles in various cellular processes, including development, cell growth, proliferation, differentiation, cell cycle, and apoptosis. ${ }^{7}$ In addition to the involvement in these biological processes, accumulating studies have reported that the dysregulation of miRs can contribute to a number of diseases, including cancer. Several miRs have been found to be upregulated or downregulated in several cancer tissues compared with the normal tissues of origin, implying that these miRs may function as either oncogenes or tumor suppressors with a cancer-specific manner. ${ }^{8,9}$ miR-99a, together with miR-100, belongs to the miR-99 family, which has been reported to be implicated into carcinogenesis and cancer progression of various human malignancies. miR-99a, located in intron 13 of the C21orf34 gene at chromosome $21 \mathrm{q},{ }^{10}$ has been observed to be deregulated in head and neck squamous cell carcinoma, ${ }^{11}$ squamous cell lung carcinoma, ${ }^{12-14}$ hepatocellular carcinoma, ${ }^{15}$ ovarian carcinoma, ${ }^{16}$ bladder cancer, ${ }^{17,18}$ and prostate cancer ${ }^{19}$ and has been reported to exert an antitumor activity in these malignancies.

Mammalian target of rapamycin (mTOR), an evolutionarily conserved serine/threonine protein kinase, belongs to the phosphoinositide-3-kinase (PI3 K)-related kinase family. ${ }^{20}$ mTOR mainly controls protein synthesis via phosphorylation of its downstream targets and interacts with several proteins to form two distinct complexes: mTOR complex 1 and $2 .{ }^{21}$ Recent studies have indicated that the dysregulation of the mTOR signaling pathway may be involved in various human cancers with gain- or loss-of-function mutants leading to neoplastic transformation. ${ }^{22-30}$ Our research group previously found that the aberrant expression of mTOR might be an independent prognostic marker of human osteosarcoma. ${ }^{31}$ Although $m$ TOR has been reported to be a target gene of miR-99a, ${ }^{32-34}$ the involvement of miR-99a in human osteosarcoma remains unclear. Thus, the aim of this study was to investigate the clinical significance of miR-99a/mTOR axis in this disease.

\section{Materials and methods Patients and tissue samples}

The collection and the use of all tissue samples in the present study were approved by the Research Ethics Committee of The Affiliated Huai' an Hospital of Xuzhou Medical College, People's Republic of China (No HA20130068). Written informed consent was obtained from all the patients. All specimens were handled and made anonymous according to the ethical and legal standards.

A total of 130 tumor tissues and self-matched noncancerous bone tissues collected from 130 patients with osteosarcoma were retrospectively enrolled according to the surgical pathology records of The Affiliated Huai'an Hospital of Xuzhou Medical College, from 2000 to 2008. The patients received X-ray, computed tomography (CT), magnetic resonance imaging (MRI), and bone scintigraphy for the diagnosis. All the tumors were confirmed pathologically from the specimens obtained from surgery. All the tissues analyzed were obtained after treatment with neoadjuvant chemotherapy. All patients received the uniform preoperative multiagent chemotherapy following the initial biopsy. The cytotoxic drugs used as preoperative chemotherapy were cis-diamminedichloroplatinum, adriamycin, vincristine, ifosfamide, and high-dose methotrexate. The resected specimens were analyzed histologically for response to chemotherapy according to the criteria released previously; the corresponding clinical information was obtained from medical records. ${ }^{35}$ The clinical and pathologic parameters were obtained from the pathological reports and presented in Table 1.

All 130 patients with osteosarcomas underwent follow-up from 3 months to 102 months (median, 48 months). The follow-up was ended on June 30, 2013. Patients were monitored with $\mathrm{CT}$ performed every 3 months during the first 3 years after chemotherapy, every 4 months during years 4 and 5, and every 6 months thereafter. The development of local recurrence and distant metastases was detected by $\mathrm{CT}$ scans or MRI. All cases were independently reviewed by two pathologists and discrepancies resolved by consensus review. Of 130 patients with osteosarcomas, 88 (67.69\%) patients were alive and $42(32.31 \%)$ patients had died of the disease. Overall survival time was calculated from the date of the initial surgical operation to death. Disease-free survival was calculated from the date of the initial surgical 
Table I Associations of miR-99a and/or mTOR mRNA expressions with the clinicopathological characteristics of primary osteosarcoma

\begin{tabular}{|c|c|c|c|c|c|c|c|}
\hline $\begin{array}{l}\text { Clinicopathological } \\
\text { characteristics }\end{array}$ & $\begin{array}{l}\text { No of patients } \\
(n, \%)\end{array}$ & miR-99a-low (\%) & $P$-value & mTOR-high (\%) & $P$-value & $\begin{array}{l}\text { miR-99a-lowl } \\
\text { mTOR-high (\%) }\end{array}$ & $P$-value \\
\hline \multicolumn{8}{|l|}{ Age (years) } \\
\hline$<20$ & $58(44.62)$ & $30(51.72)$ & NS & $30(51.72)$ & NS & $20(34.48)$ & NS \\
\hline$\geq 20$ & $72(55.38)$ & $40(55.56)$ & & $38(52.78)$ & & 28 (38.89) & \\
\hline \multicolumn{8}{|l|}{ Sex } \\
\hline Male & 92 (70.77) & $50(54.35)$ & NS & 47 (5I.09) & NS & 32 (34.78) & NS \\
\hline Female & $38(29.23)$ & $20(52.63)$ & & $21(55.26)$ & & $16(42.11)$ & \\
\hline \multicolumn{8}{|l|}{ Tumor size } \\
\hline$\leq 5 \mathrm{~cm}$ & $60(46.15)$ & $32(53.33)$ & NS & $30(50.00)$ & NS & $20(33.33)$ & NS \\
\hline$>5 \mathrm{~cm}$ & $70(53.85)$ & $38(54.29)$ & & $38(54.29)$ & & $28(40.00)$ & \\
\hline \multicolumn{8}{|l|}{ Tumor location } \\
\hline Femur & $60(46.15)$ & $32(53.33)$ & NS & $32(53.33)$ & NS & $23(38.33)$ & NS \\
\hline Tibia & $40(30.77)$ & $22(55.00)$ & & $20(50.00)$ & & $15(37.50)$ & \\
\hline Humerus & $24(18.45)$ & $13(54.17)$ & & $13(54.17)$ & & $8(33.33)$ & \\
\hline Fibula & $6(4.62)$ & $3(50.00)$ & & $3(50.00)$ & & $2(33.33)$ & \\
\hline \multicolumn{8}{|l|}{ Surgical stage } \\
\hline IIA & $55(42.31)$ & $20(36.36)$ & 0.01 & $20(36.36)$ & 0.01 & $10(18.18)$ & 0.008 \\
\hline$\| \mathrm{IB} / \mathrm{II}$ & 75 (57.69) & $50(66.67)$ & & $48(64.00)$ & & $38(50.67)$ & \\
\hline \multicolumn{8}{|l|}{ Metastasis } \\
\hline No & $73(56.15)$ & 21 (28.77) & 0.006 & $18(24.66)$ & 0.005 & $6(8.22)$ & 0.002 \\
\hline Yes & $57(43.85)$ & $49(85.96)$ & & $50(87.72)$ & & $42(73.68)$ & \\
\hline \multicolumn{8}{|l|}{ Recurrence } \\
\hline No & $76(58.46)$ & 25 (32.89) & 0.01 & $22(28.95)$ & 0.006 & $8(10.53)$ & 0.002 \\
\hline Yes & $54(41.54)$ & $45(83.33)$ & & $46(85.19)$ & & $40(74.07)$ & \\
\hline \multicolumn{8}{|l|}{ Histological subtype } \\
\hline Osteoblastic & $70(53.85)$ & $35(50.00)$ & NS & $35(50.00)$ & NS & $25(35.7 I)$ & NS \\
\hline Chondroblastic & $28(21.54)$ & $16(57.14)$ & & $16(57.14)$ & & $10(35.71)$ & \\
\hline Fibroblastic & $21(16.15)$ & $12(57.14)$ & & II (52.38) & & $7(33.33)$ & \\
\hline Mixed type & $6(4.62)$ & $4(66.67)$ & & $3(50.00)$ & & $3(50.00)$ & \\
\hline Small type & $5(3.85)$ & $3(60.00)$ & & $3(60.00)$ & & $3(60.00)$ & \\
\hline \multicolumn{8}{|c|}{ Response to chemotherapy } \\
\hline Good & $75(53.85)$ & $30(40.00)$ & 0.02 & $28(37.33)$ & 0.02 & $10(13.33)$ & 0.01 \\
\hline Poor & $55(46.15)$ & $40(72.73)$ & & $40(72.73)$ & & $38(69.09)$ & \\
\hline
\end{tabular}

Abbreviations: miR, microRNA; NS, not significant.

operation to the date of second cancer, tumor recurrence, distant metastases, or death from any cause.

\section{Quantitative real-time polymerase chain reaction}

The expression levels of miR-99a and mTOR mRNA in 130 pairs of osteosarcoma and matched noncancerous bone tissues were detected by quantitative real-time polymerase chain reaction (qRT-PCR). Total RNA in fresh tissues was extracted by using TRIzol reagent (Thermo Fisher Scientific, Waltham, MA, USA) based on the manufacturer's instructions. For the detection of miR-99a and RNU6B used as internal controls, TaqMan MicroRNA Assays (Thermo Fisher Scientific) with primers specific to miR-99a and RNU6B were used. Reverse transcription was performed using One Step PrimeScript
miRNA cDNA Synthesis Kit (Thermo Fisher Scientific), and qRT-PCR was performed using SYBR Premix Ex TaqII (Thermo Fisher Scientific). qRT-PCR primer sequences were as follows: miR-99a, forward 5'-GGA ACC CGT AGA TCC GAT- $3^{\prime}$ and reverse $5^{\prime}$-GTG CAG GGT CCG AGG T-3'; RNU6B, forward 5'-ACA GUA GUC UGC ACA UUG GUU A- $3^{\prime}$ and reverse $5^{\prime}$-ACG CAA ATT CGT GAA GCG TT- $3^{\prime}$. For the detection of mTOR mRNA and $\beta$-actin mRNA used as internal controls, reverse transcription was performed using PrimeScript RT Master Mix (Thermo Fisher Scientific), and qRT-PCR was carried out using SYBR Premix Ex Taq II (Thermo Fisher Scientific). qRT-PCR primer sequences were as follows: $m T O R$, forward $5^{\prime}$-AGA TTT AAT GGA GGC CCA GG-3' and reverse 5'-GGC CTC TGT TTG GAT GTG AT-3'; $\beta$-actin, forward 5'-GGT CAG AAG 
GAC TCC TAT GTG G-3' and reverse 5'-TGT CGT CCC AGT TGG TAA CA-3'. qRT-PCR was performed using an ABI 7500 Real-Time PCR Detection System (Thermo Fisher Scientific). The threshold cycle $\left(C_{t}\right)$ was defined as the fractional cycle number at which the fluorescence passed the fixed threshold. Each sample was detected three times, and the relative expression level of miR-99a/mTOR to RNU6/ $\beta$-actin was calculated using the $2^{-\Delta C_{\mathrm{t}}}$ method, where $\Delta C_{\mathrm{t}}=\left(C_{\mathrm{t} \text { miR-99a/mTOR }} / C_{\mathrm{t} \text { RNU6/3-actin }}\right)$. The median values of miR99a and $m$ TOR mRNA expression levels in osteosarcoma tissues were used as cutoff points for dividing miR-99a-low/ high groups and $m T O R$-low/high groups, respectively.

\section{Statistical analysis}

SPSS software for Windows (version 13.0; SPSS Inc., Chicago, IL, USA) was used to perform statistical analyses in this study. Fisher's exact test was used for any $2 \times 2$ tables, Pearson $\chi^{2}$ test for non- $2 \times 2$ tables, chi-square trend test for ordinal datum, and Kaplan-Meier and Cox regression methods for the question of survival analysis. Spearman's rank correlation is used to analyze the correlation between the expression of miR-99a and $m$ TOR mRNA. Differences were considered statistically significant when $P$ - was $<0.05$.

\section{Results}

\section{Dysregulation of miR-99a/mTOR axis in}

\section{human osteosarcoma tissues}

The expression levels of miR-99a (tumor vs normal: 2.11 \pm 1.03 vs 4.69 $\pm 1.21, P<0.001$; Figure 1A) and $m T O R$ mRNA (tumor vs normal: $4.40 \pm 1.13$ vs $1.74 \pm 0.85, P<0.001$; Figure $1 \mathrm{~A}$ ) in osteosarcoma tissues were, respectively, lower and higher

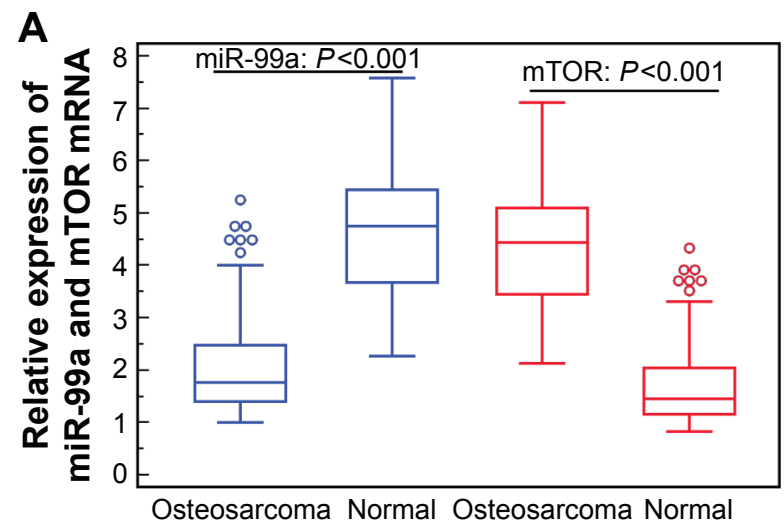

Figure I Dysregulation of miR-99a/mTOR axis in human osteosarcoma tissues.

Notes: (A) miR-99a (tumor vs normal: $2.1 \mathrm{I} \pm \mathrm{I} .03$ vs $4.69 \pm \mathrm{I} .2 \mathrm{I}, \mathrm{P}<0.00 \mathrm{I}$ ) and $m$ TOR mRNA (tumor vs normal: $4.40 \pm \mathrm{I} .13$ vs I.74 $\pm 0.85, P<0.00 \mathrm{I}$ ) expression levels in osteosarcoma tissues were, respectively, lower and higher than those in noncancerous bone tissues. (B) Expression levels of miR-99a in osteosarcoma tissues were negatively correlated with those of $m$ TOR mRNA $(r=-0.36, P=0.02)$.

Abbreviation: miR, microRNA.

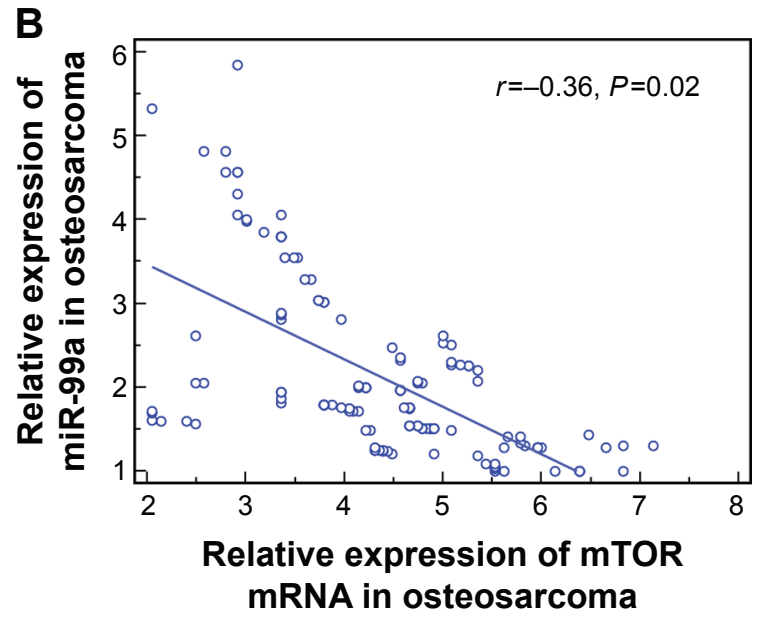

than those in noncancerous bone tissues. Of 130 patients with osteosarcoma, $70(53.85 \%)$ and 68 (52.31\%) had low miR-99a expression and high mTOR mRNA expression, respectively; 20 (15.38\%) had both high expression of miR99a and mTOR; 22 (16.92\%) had both low expression of miR-99a and mTOR; 40 (30.77\%) had miR-99a-high and mTOR-low expression; and 48 (36.92\%) had miR-99a-low and $m T O R$-high expression. The expression levels of miR-99a in osteosarcoma tissues were negatively correlated with those of $m$ TOR mRNA ( $r=-0.36, P=0.02$; Figure 1B).

\section{Dysregulation of miR-99a/mTOR axis associates with malignant progression of human osteosarcoma}

Table 1 summarized the associations of miR-99a and/or mTOR mRNA expression with the clinicopathological characteristics of patients with osteosarcoma. The statistical analyses revealed that miR-99a-low and/or mTOR-high expression were all significantly associated with advanced surgical stage, positive metastasis and recurrence, and poor response to chemotherapy (all $P<0.05$ ). There was no significant associations with age, sex, tumor size, tumor location, or histological subtype (all $P>0.05$; Table 1).

\section{Dysregulation of miR-99a/mTOR axis predicts poor prognosis in human osteosarcoma}

Associations of miR-99a and/or mTOR expression in osteo sarcoma tissues with patients' prognosis were further evaluated by Kaplan-Meier analysis and log-rank test. As shown in Figure 2, patients with osteosarcoma with low miR-99a 
expression and high $m T O R$ expression had both shorter disease-free survival (Figure 2A and C, respectively, both $P<0.001$ ) and shorter overall survival (Figure 2B and $\mathrm{D}$, respectively, both $P<0.001$ ) than those with high miR99a expression and low $m$ TOR expression. The association between the combined expression of miR-99a/mTOR and the survival rates was also tested by Kaplan-Meier analysis. The results by pairwise comparisons showed that miR-99a-low/mTOR-high subjects had the poorest prognosis in miR-99a-low (high)/mTOR-high (low) groups $(P<0.001$; Figure $2 \mathrm{E}$ and $\mathrm{F}$ ).

Moreover, univariate analysis showed that the advanced surgical stage, positive recurrence and metastasis, miR-99a low expression, $m T O R$ mRNA high expression, the combined miR-99a-low/mTOR-high expression, and the poor
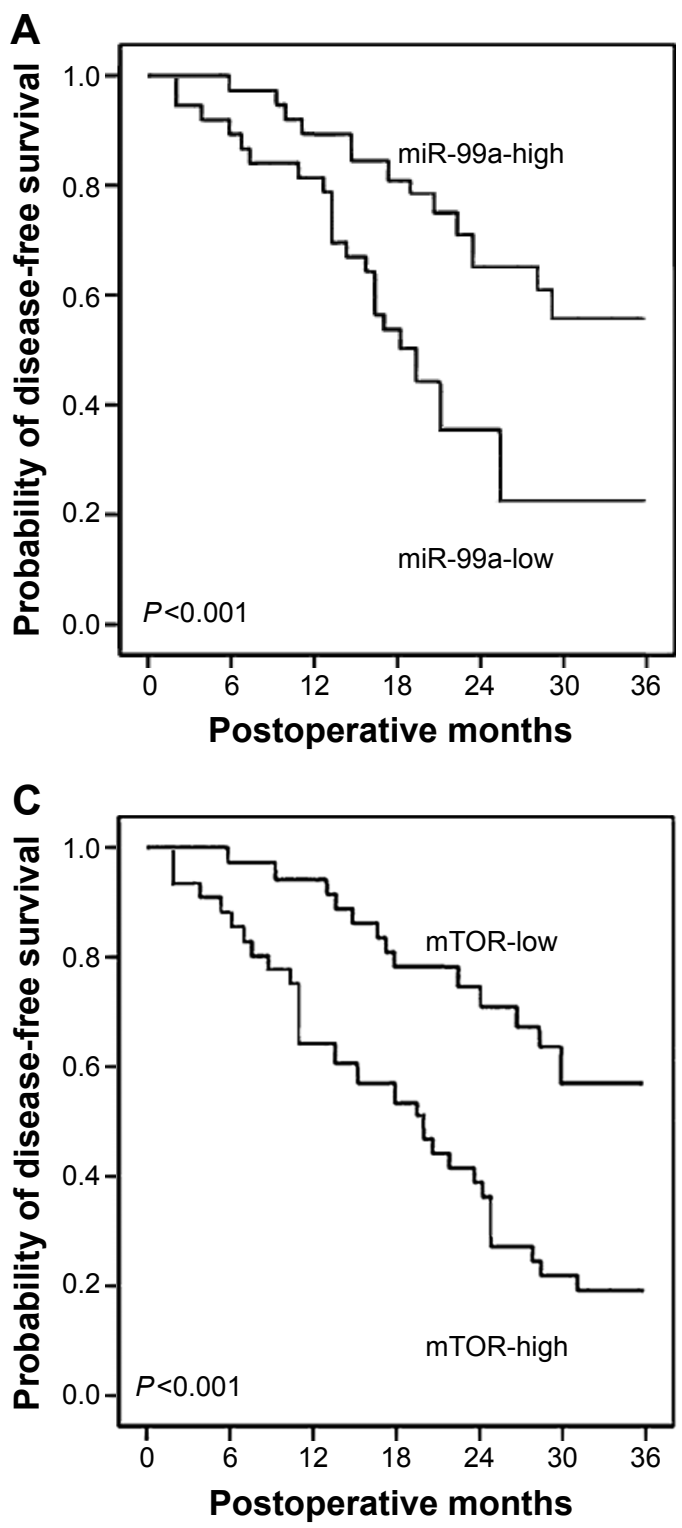

response to chemotherapy were all significantly correlated with poor overall survival ( $P \leq 0.001, P \leq 0.006, P<0.001$, $P<0.001, P<0.001$, and $P<0.001$, respectively; Table 2) and disease-free survival $(P \leq 0.001, P \leq 0.01, P<0.001$, $P<0.001, P<0.001$, and $P<0.001$, respectively; Table 2) of patients with osteosarcoma.

Furthermore, multivariate analysis as shown in Table 3 showed that the surgical stage (both $P=0.001$ ), the status of recurrence (both $P=0.022)$ and metastasis $(P=0.009$ and $P=0.013$, respectively), miR-99a expression (both $P=0.01$ ), mTOR mRNA expression (both $P=0.01$ ), the combined miR$99 \mathrm{a} / m$ TOR expression (both $P=0.001$ ), and the response to chemotherapy ( $P=0.011$ and $P=0.016$, respectively) were all independent prognostic factors for overall and disease-free survivals.
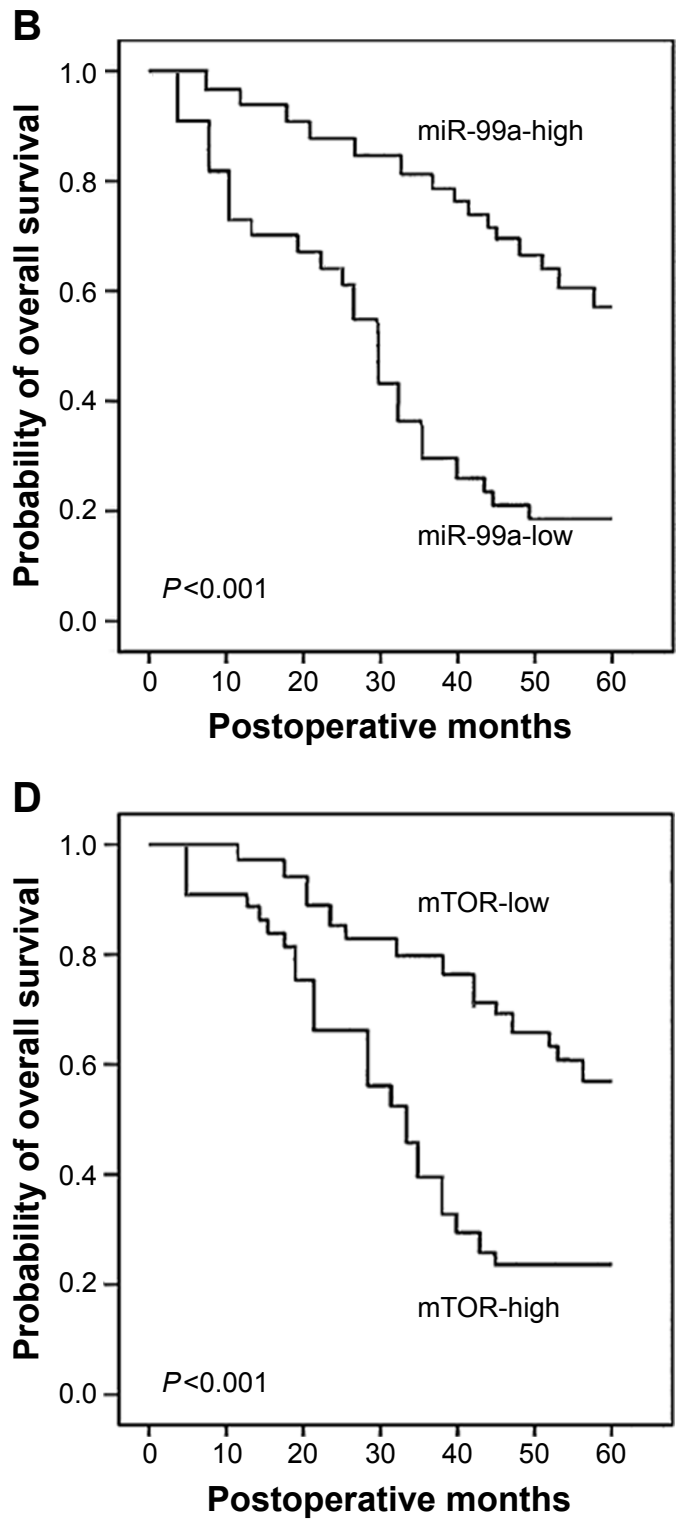

Figure 2 (Continued) 

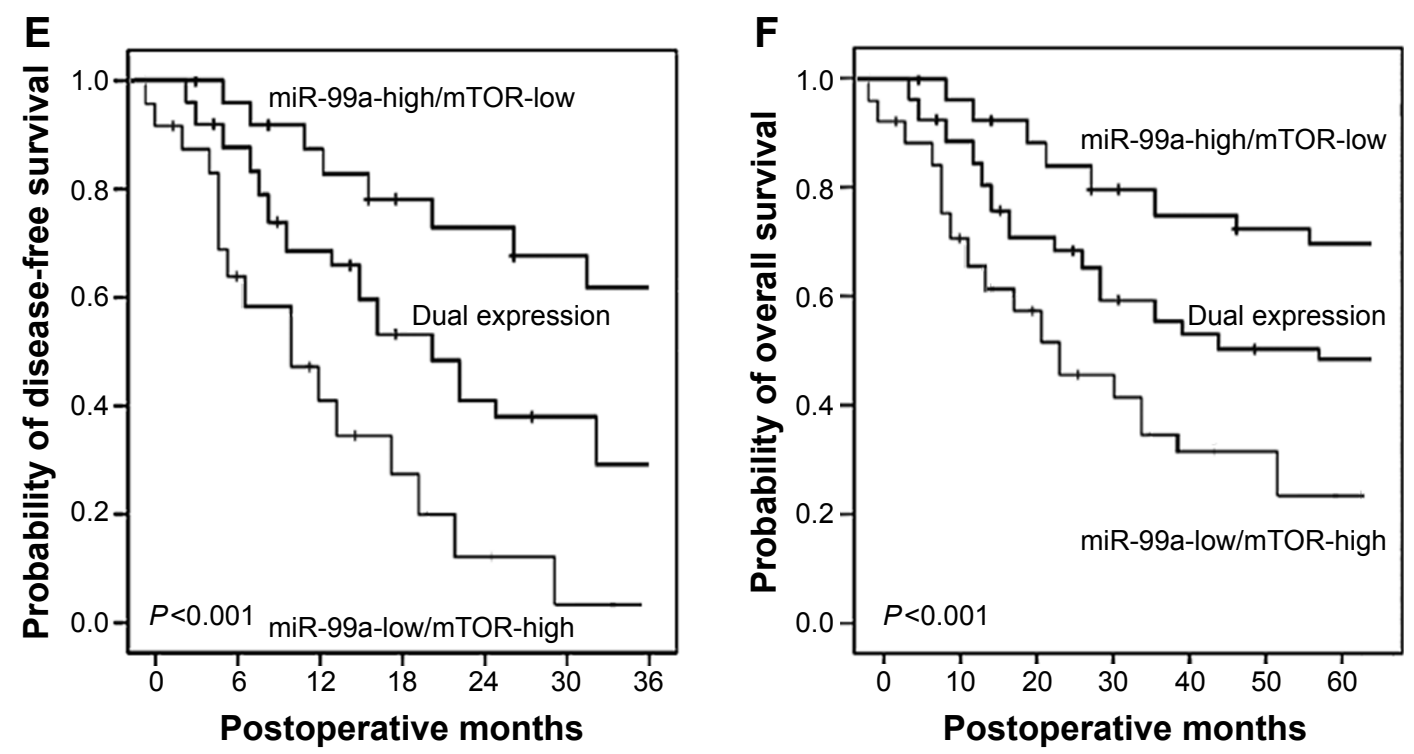

Figure 2 Associations of miR-99a expression (A and B), mTOR expression (C and D) and the co-expression of miR-99a/mTOR (E) and (F) with disease-free and overall survivals of patients with primary osteosarcoma.

Abbreviation: miR, microRNA.

\section{Discussion}

Screening novel markers for human osteosarcoma may be essential for the accurate identification of the biological features of tumors, the improvement of targeted therapies, and the prediction of patients' outcome. Growing evidence shows that the dysregulation of miR-target mRNA axis can contribute to tumorigenesis, tumor progression, and prognosis. In the current study, we demonstrated that miR-99a and its target gene $m T O R$ were, respectively, expressed at low and high levels in clinical osteosarcoma tissues.

Table 2 Univariate analysis of prognostic parameters in patients with osteosarcomas by Cox regression analysis

\begin{tabular}{|c|c|c|c|c|}
\hline \multirow[t]{2}{*}{ Variables } & \multicolumn{2}{|c|}{ Overall survival } & \multicolumn{2}{|c|}{ Disease-free survival } \\
\hline & $P$-value & $\mathbf{R R}$ & $P$-value & $\mathbf{R R}$ \\
\hline \multicolumn{5}{|l|}{ Age at diagnosis (years) } \\
\hline$<20$ vs $\geq 20$ & 0.125 & 0.691 & 0.118 & 0.651 \\
\hline \multicolumn{5}{|l|}{ Sex } \\
\hline Male vs female & 0.112 & 0.916 & 0.110 & 0.846 \\
\hline \multicolumn{5}{|l|}{ Tumor size $(\mathrm{cm})$} \\
\hline$<5.0$ vs $\geq 5.0$ & 0.312 & 0.568 & 0.310 & 0.521 \\
\hline \multicolumn{5}{|l|}{ Tumor location } \\
\hline Femur vs tibia and others & 0.200 & 0.899 & 0.213 & 0.887 \\
\hline \multicolumn{5}{|l|}{ Surgical stage } \\
\hline IIA vs IIB/III & $<0.00 \mathrm{I}$ & 8.782 & $<0.001$ & 8.312 \\
\hline \multicolumn{5}{|l|}{ Histological subtype } \\
\hline Osteoblastic vs others & 0.116 & 0.925 & 0.119 & 0.921 \\
\hline \multicolumn{5}{|l|}{ Recurrence } \\
\hline No vs yes & 0.006 & 4.732 & 0.01 & 4.098 \\
\hline \multicolumn{5}{|l|}{ Metastasis } \\
\hline No vs yes & $<0.001$ & 8.279 & $<0.001$ & 8.132 \\
\hline \multicolumn{5}{|l|}{ Response to chemotherapy } \\
\hline Good vs poor & $<0.001$ & 8.026 & $<0.001$ & 7.969 \\
\hline \multicolumn{5}{|l|}{ miR-99a expression } \\
\hline Low vs high & $<0.001$ & 8.822 & $<0.001$ & 8.066 \\
\hline \multicolumn{5}{|l|}{ mTOR expression } \\
\hline Low vs high & $<0.001$ & 7.813 & $<0.001$ & 7.268 \\
\hline \multicolumn{5}{|l|}{ miR-99a/mTOR expression } \\
\hline miR-99a-low/mTOR-high vs others & $<0.001$ & 8.826 & $<0.001$ & 8.292 \\
\hline
\end{tabular}

Abbreviations: miR, microRNA; RR, relative risk. 
Table 3 Multivariate analysis of prognostic parameters in patients with osteosarcomas by Cox regression analysis

\begin{tabular}{|c|c|c|c|c|}
\hline \multirow[t]{2}{*}{ Prognostic factors } & \multicolumn{2}{|l|}{ Overall survival } & \multicolumn{2}{|l|}{ Disease-free survival } \\
\hline & $\begin{array}{l}\text { Relative risk } \\
\text { (95\% confidence interval) }\end{array}$ & $P$-value & $\begin{array}{l}\text { Relative risk } \\
\text { (95\% confidence interval) }\end{array}$ & $P$-value \\
\hline Recurrence & $2.167(0.980-4.561)$ & 0.022 & $2.020(0.972-4.416)$ & 0.022 \\
\hline Surgical stage & $6.668(1.310-14.968)$ & 0.001 & $6.392(1.286-14.129)$ & 0.001 \\
\hline Metastasis & $5.020(1.05 \mathrm{I}-11.109)$ & 0.009 & $5.006(1.109-11.088)$ & 0.013 \\
\hline Response to chemotherapy & $3.252(0.932-7.867)$ & 0.01 & $3.158(0.973-7.567)$ & 0.01 \\
\hline miR-99a expression & $5.232(1.022-12.398)$ & 0.01 & $5.176(1.003-11.928)$ & 0.01 \\
\hline mTOR expression & $5.312(1.021-12.299)$ & 0.01 & $5.229(1.033-12.018)$ & 0.01 \\
\hline miR-99a/mTOR expression & $6.891(1.398-15.296)$ & 0.001 & $6.693(1.312-14.895)$ & 0.001 \\
\hline
\end{tabular}

Abbreviation: miR, microRNA.

The downregulation of miR-99a expression and the upregulation of $m T O R$ mRNA, alone or in combination, were all significantly correlated with the recurrence, the metastasis, and the response to chemotherapy of patients with osteosarcoma. Using multivariate Cox regression analysis, the aberrant expression of miR-99a and/or mTOR mRNA was shown to be independent predictors for worse prognosis in patients with osteosarcoma. To the best of our knowledge, this is the first time to determine the expression patterns and clinical significance of miR-99a/mTOR axis in the progression and prognosis of human osteosarcoma.

miR-99a has been reported to be frequently lost or expressed at a reduced level and to function as a tumor suppressor in various human cancers. For example, Wu et al ${ }^{17}$ found that miR-99a inhibited cell proliferation, migration, and invasion in bladder cancer cell lines by directly targeting fibroblast growth factor receptor 3 . Yu et al ${ }^{12}$ reported that miR-99a was downregulated in non-small-cell lung cancer tissues, which was significantly associated with last-stage and tumor metastasis in patients with this malignancy. Further functional experiments also found that the overexpression of miR-99a could inhibit cell proliferation, migration, and invasion of non-small-cell lung cancer cells in vitro and tumor metastasis of non-small-cell lung cancer in vivo. Wang et $\mathrm{a}^{36}$ indicated that the reduced miR-99a expression was highly associated with lymph node metastasis and shorter overall survival of patients with breast cancer. Gain- and loss-of-function studies of this research group revealed that miR-99a efficiently inhibited breast cancer cell proliferation, migration, and invasion. Li et a ${ }^{15}$ showed that miR-99a expression was correlated with the survival of patients with hepatocellular carcinoma, and the restoration of this miR suppressed the growth of hepatocellular carcinoma cells in vitro and in vivo by targeting insulin-like growth factor 1 receptor and $m T O R$. Cui et al ${ }^{37}$ found that miR-99a was remarkably downregulated in renal cell carcinoma and low expression level of miR-99a was correlated with poor survival of patients with renal cell carcinoma. Further functional experiments of these authors validated the inhibitory effects of miR-99a on the growth of cancer cells, clonability, migration, and invasion as well as induced G1-phase cell cycle arrest in vitro, and the tumor growth in murine xenograft models. Jiang et a ${ }^{16}$ also observed that the overexpression of miR-99a could significantly inhibit epithelial ovarian cancer cell proliferation in vitro by decreasing the expression of FGFR3. Although these previous findings suggest the important roles of miR-99a in the suppression of tumor aggressive progression and malignant phenotypes of multiple cancer types, its definite function of human osteosarcoma has not been described yet.

Recent functional analyses have shown the regulatory effect of miR-99a on $m T O R$ and identified $m T O R$ as a direct target of miR-99a ${ }^{24-26}$ For example, Gu et al ${ }^{38}$ found that the transfection of miR-99a mimics could induce the decreased expression of mTOR protein in human lung adenocarcinoma cells, while transfection of miR-99a inhibitor could induce the increased expression of mTOR protein, implying that $m T O R$ was a direct target of miR-99a in lung adenocarcinoma cells. Yang et $\mathrm{al}^{24}$ performed the qRT-PCR, and Western blot assays indicated that the overexpression of miR-99a could suppress the expression of $m T O R$ in breast cancer cells. Huang et $\mathrm{al}^{10}$ also confirmed the regulatory effects of miR-99a on $m T O R$ in human anaplastic thyroid cancer by luciferase assay. Our research group performed the immunohistochemistry and confirmed the overexpression of mTOR protein in osteosarcoma tissues. We also found the significant associations between mTOR overexpression and tumor progression and prognosis in patients with osteosarcoma. ${ }^{23}$ These previous findings prompted us to investigate the clinical significance of miR-99a/mTOR interaction in this malignancy. Here, our results showed that miR-99a was decreased, while $m T O R$ mRNA was increased in osteosarcoma tissues. We also proved that the relative expression levels of miR-99a and mTOR mRNA, alone or in combination, were also associated 
with advanced clinicopathological characteristics of patients with osteosarcoma. Moreover, miR-99a low and mTOR mRNA high expressions were both correlated with shorter overall and disease-free survivals and could be independent prognostic factors in patients with osteosarcoma.

More interestingly, we also found that the patients with osteosarcoma with miR-99a-high/mTOR-low expression, among four different statuses of miR-99a/mTOR co-expression, had the best outcome, while the miR-99alow/mTOR-high had the worst. Multivariate analysis revealed that the miR-99a-low/mTOR-high co-expression may be an independent prognostic indicator for osteosarcoma. The advantages of miR-99a/mTOR co-expression to individual miR-99a or $m$ TOR in predicting the outcome of osteosarcoma have been shown in our result.

\section{Conclusion}

In conclusion, our data reveal the crucial role of miR-99a/ $m T O R$ axis in the malignant progression of human osteosarcoma, implying that conjoined expression of miR-99a and $m T O R$ may offer an attractive novel prognostic marker for this disease.

\section{Acknowledgments}

This research was supported by grants from Jiangsu Provincial Special Program of Medical Science (No BL2012004), Jiangsu Provincial Clinical Orthopedic Center, and the Priority Academic Program Development of Jiangsu Higher Education Institutions (PAPD), and the Huai'an Technology Support Program (social development) funded projects (No HAS2015009-4).

\section{Author contributions}

All the authors participated in the design, interpretation of the studies, and analysis of the data and critically revised the manuscript. JZ, FC, QZ, and WP conducted the experiments; $\mathrm{XW}$ and $\mathrm{JZ}$ collected clinical samples; JZ and FC wrote the manuscript; and LN performed data analysis.

\section{Disclosure}

The authors report no conflicts of interest in this work.

\section{References}

1. Kansara M, Teng MW, Smyth MJ, Thomas DM. Translational biology of osteosarcoma. Nat Rev Cancer. 2014;14:722-735.

2. Moore DD, Luu HH. Osteosarcoma. Cancer Treat Res. 2014;162: 65-92.

3. Zhou W, Hao M, Du X, Chen K, Wang G, Yang J. Advances in targeted therapy for osteosarcoma. Discov Med. 2014;17:301-307.

4. Botter SM, Neri D, Fuchs B. Recent advances in osteosarcoma. Curr Opin Pharmacol. 2014;16:15-23.
5. Iadevaia $\mathrm{V}$, Gerber AP. Combinatorial control of mRNA fates by RNA-binding proteins and non-coding RNAs. Biomolecules. 2015;5: 2207-2222.

6. Ohtsuka M, Ling H, Doki Y, Mori M, Calin GA. MicroRNA processing and human cancer. J Clin Med. 2015;4:1651-1667.

7. Sampson VB, Yoo S, Kumar A, Vetter NS, Kolb EA. MicroRNAs and potential targets in osteosarcoma: review. Front Pediatr. 2015;3:69.

8. Zhang J, Yan YG, Wang C, Zhang SJ, Yu XH, Wang WJ. MicroRNAs in osteosarcoma. Clin Chim Acta. 2015;444:9-17.

9. Orellana EA, Kasinski AL. MicroRNAs in cancer: a historical perspective on the path from discovery to therapy. Cancers (Basel). 2015;7: $1388-1405$.

10. Huang HG, Luo X, Wu S, Jian B. MiR-99a inhibits cell proliferation and tumorigenesis through targeting mTOR in human anaplastic thyroid cancer. Asian Pac J Cancer Prev. 2015;16:4937-4944.

11. Chen Z, Jin Y, Yu D, et al. Down-regulation of the microRNA-99 family members in head and neck squamous cell carcinoma. Oral Oncol. 2012; 48:686-691.

12. Yu SH, Zhang CL, Dong FS, Zhang YM. miR-99a suppresses the metastasis of human non-small cell lung cancer cells by targeting AKT1 signaling pathway. J Cell Biochem. 2015;116:268-276.

13. Song Y, Dou H, Wang P, et al. A novel small-molecule compound diaporine A inhibits non-small cell lung cancer growth by regulating miR-99a/mTOR signaling. Cancer Biol Ther. 2014;15:1423-1430.

14. Chen C, Zhao Z, Liu Y, Mu D. microRNA-99a is downregulated and promotes proliferation, migration and invasion in non-small cell lung cancer A549 and H1299 cells. Oncol Lett. 2015;9:1128-1134.

15. Li D, Liu X, Lin L, et al. MicroRNA-99a inhibits hepatocellular carcinoma growth and correlates with prognosis of patients with hepatocellular carcinoma. J Biol Chem. 2011;286:36677-36685.

16. Jiang H, Qu L, Wang Y, Cong J, Wang W, Yang X. miR-99a promotes proliferation targeting FGFR3 in human epithelial ovarian cancer cells. Biomed Pharmacother. 2014;68:163-169.

17. Wu D, Zhou Y, Pan H, Zhou J, Fan Y, Qu P. microRNA-99a inhibiting cell proliferation, migration and invasion by targeting fibroblast growth factor receptor 3 in bladder cancer. Oncol Lett. 2014;7:1219-1224.

18. Feng Y, Kang Y, He Y, et al. microRNA-99a acts as a tumor suppressor and is down-regulated in bladder cancer. BMC Urol. 2014; 14:50.

19. Someya M, Yamamoto H, Nojima M, et al. Relation between Ku80 and microRNA-99a expression and late rectal bleeding after radiotherapy for prostate cancer. Radiother Oncol. 2015;115:235-239.

20. Xia $\mathrm{P}, \mathrm{Xu} X Y$. PI3K/Akt/mTOR signaling pathway in cancer stem cells: from basic research to clinical application. Am J Cancer Res. 2015;5: 1602-1609.

21. Perl A. mTOR activation is a biomarker and a central pathway to autoimmune disorders, cancer, obesity, and aging. Ann N Y Acad Sci. 2015; 1346:33-44.

22. Gentilella A, Kozma SC, Thomas G. A liaison between mTOR signaling, ribosome biogenesis and cancer. Biochim Biophys Acta. 2015;1849: 812-820.

23. Cargnello M, Tcherkezian J, Roux PP. The expanding role of mTOR in cancer cell growth and proliferation. Mutagenesis. 2015;30: 169-176.

24. Yang J, Cheng D, Zhou S, Zhu B, Hu T, Yang Q. Overexpression of $\mathrm{X}$-box binding protein 1 (XBP1) correlates to poor prognosis and upregulation of PI3K/mTOR in human osteosarcoma. Int J Mol Sci. 2015; 16:28635-28646.

25. Horie R, Nakamura O, Yamagami Y, et al. Apoptosis and antitumor effects induced by the combination of an mTOR inhibitor and an autophagy inhibitor in human osteosarcoma MG63 cells. Int J Oncol. 2016;48: $37-44$.

26. Jiang H, Zeng Z. Dual mTORC1/2 inhibition by INK-128 results in antitumor activity in preclinical models of osteosarcoma. Biochem Biophys Res Commun. 2015;468:255-261.

27. Liu Y, Bi T, Dai W, et al. Lupeol induces apoptosis and cell cycle arrest of human osteosarcoma cells through PI3K/AKT/mTOR pathway. Technol Cancer Res Treat. Epub 2015 Oct 6. 
28. Song R, Tian K, Wang W, Wang L. P53 suppresses cell proliferation, metastasis, and angiogenesis of osteosarcoma through inhibition of the PI3K/AKT/mTOR pathway. Int J Surg. 2015;20:80-87.

29. Gupte A, Baker EK, Wan SS, et al. Systematic screening identifies dual PI3K and mTOR inhibition as a conserved therapeutic vulnerability in osteosarcoma. Clin Cancer Res. 2015;21:3216-3229.

30. Niu NK, Wang ZL, Pan ST, et al. Pro-apoptotic and pro-autophagic effects of the aurora kinase A inhibitor alisertib (MLN8237) on human osteosarcoma U-2 OS and MG-63 cells through the activation of mitochondria-mediated pathway and inhibition of $\mathrm{p} 38 \mathrm{MAPK} / \mathrm{PI} 3 \mathrm{~K} / \mathrm{Akt} /$ mTOR signaling pathway. Drug Des Devel Ther. 2015;9:1555-1584.

31. Zhou Q, Deng Z, Zhu Y, Long H, Zhang S, Zhao J. mTOR/p70S6K signal transduction pathway contributes to osteosarcoma progression and patients' prognosis. Med Oncol. 2010;27:1239-1245.

32. Hu Y, Zhu Q, Tang L. MiR-99a antitumor activity in human breast cancer cells through targeting of mTOR expression. PLoS One. 2014;9: e92099.

33. Yang Z, Han Y, Cheng K, Zhang G, Wang X. miR-99a directly targets the mTOR signalling pathway in breast cancer side population cells. Cell Prolif. 2014;47:587-595.
34. Sun J, Chen Z, Tan X, et al. MicroRNA-99a/100 promotes apoptosis by targeting mTOR in human esophageal squamous cell carcinoma. Med Oncol. 2013;30:411.

35. Bielack SS, Kempf-Bielack B, Delling G, et al. Prognostic factors in high-grade osteosarcoma of the extremities or trunk: an analysis of 1,702 patients treated on neoadjuvant cooperative osteosarcoma study group protocols. J Clin Oncol. 2002;20:776-790.

36. Wang X, Li Y, Qi W, et al. MicroRNA-99a inhibits tumor aggressive phenotypes through regulating HOXA1 in breast cancer cells. Oncotarget. 2015;6(32):32737-32747.

37. Cui L, Zhou H, Zhao H, et al. MicroRNA-99a induces G1-phase cell cycle arrest and suppresses tumorigenicity in renal cell carcinoma. BMC Cancer. 2012;12:546.

38. Gu W, Fang S, Gao L, Tan Y, Yang Z. Clinic significance of microRNA99a expression in human lung adenocarcinoma. J Surg Oncol. 2013; 108:248-255.

\section{Publish your work in this journal}

OncoTargets and Therapy is an international, peer-reviewed, open access journal focusing on the pathological basis of all cancers, potential targets for therapy and treatment protocols employed to improve the management of cancer patients. The journal also focuses on the impact of management programs and new therapeutic agents and protocols on

\section{Dovepress}

patient perspectives such as quality of life, adherence and satisfaction. The manuscript management system is completely online and includes a very quick and fair peer-review system, which is all easy to use. Visit http://www.dovepress.com/testimonials.php to read real quotes from published authors. 